From the American

Board of Family Medicine

Ann Fam Med 2018;16:473. https://doi.org/10.1370/afm.2293.

\section{NEW CENTER FOR PROFESSIONALISM AND VALUE IN HEALTH CARE OPEN IN WASHINGTON, DC}

The American Board of Family Medicine (ABFM) and the ABFM Foundation are pleased to announce the establishment of the Center for Professionalism and Value in Health Care based in Washington, DC. The Center will be led by Robert Phillips, MD, MSPH, who has been named as its founding Executive Director.

"Health care in the United States is in the midst of transformational change; professional self-regulation and the public trust are at risk. To meet this challenge, the ABFM Foundation has decided to make a strategic investment in the creation of the Center with the ultimate goal of dramatically improving health and health care," said ABFM President and CEO-Elect Warren P. Newton, MD, MPH.

The new Center aims to create space in which patients, health professionals, payers, and policy makers can work to renegotiate the social contract. "The social contract between health care professionals and the public gives clinicians the privilege of selfregulation in exchange for responsibility to act in the best interest of patients. This contract is fraying as increased employment of clinicians creates pressures to serve business interests over those of patients. The erosion of autonomy, strain of regulation, and exploding reporting burden is producing unprecedented levels of burnout," says Dr Phillips. "It has gotten so bad," continues Phillips, "that physicians are unwittingly asking many state legislatures to remove long-standing mechanisms of self-regulation and public accountability. We cannot afford to have the public question health professionals' willingness to be accountable, and patients cannot afford our surrender of that role to payers and policy makers."

The Center will seek to define value across the health care spectrum, reaching beyond medicine to engage the broader health care community as well as patients and families to consider what they believe professionalism and value mean, how to measure it, how to improve it, and how to engage and develop leaders. The Center welcomes collaboration with all others interested in professionalism and value in health care, including other specialty boards, other professions, and other organizations interested in working together on this common ground.

"The selection of Bob Phillips to lead the Center is an outstanding choice," says James C. Puffer, MD, President and CEO of the ABFM. "In his role as ABFM Vice President of Research and Policy, he helped the ABFM Research Department grow to become an influential source of information about the value of primary care. He also led the launch of the national PRIME Registry, which now helps primary care practices in 49 states liberate data from their electronic health records, thus enabling easier monitoring and improvement of quality measure reporting, and completion of certification requirements. He was instrumental in the creation and successful launch of the ABFM PHATE tool, which helps practices understand how their patients are affected by social determinants of health and how to meet their needs, as well as to support enhanced reimbursement."

Dr Phillips graduated from the University of Florida College of Medicine and completed residency training and a health services research fellowship at the University of Missouri. Prior to coming to the ABFM, he directed the Robert Graham Center for Policy Studies in Primary Care. Dr Phillips is an elected member of the National Academy of Medicine and was a Fulbright Specialist to the Netherlands and New Zealand. He currently serves on the National Committee on Vital and Health Statistics, is a Professor at Georgetown University and Virginia Commonwealth University, and maintains a continuity family medicine practice in Virginia.

Robert Cattoi, ABFM

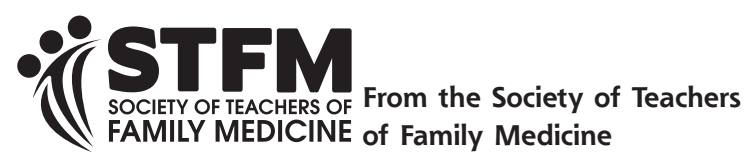

Ann Fam Med 2018;16:473-475. https://doi.org/10.1370/afm.2296.

\section{RESIDENCY FACULTY FUNDAMENTALS CERTIFICATE PROGRAM WRAPS UP SUCCESSFUL FIRST YEAR}

\section{Background}

In June 2017, STFM launched the Residency Faculty

Fundamentals Certificate Program to provide foundational training for residency faculty. The program covers: the structure and requirements of residency education; how to be an effective and efficient faculty member $;$ the nuts and bolts of 
curriculum development and teaching $;$ and strategies for assessment, feedback, and remediation of residents.

Courses include readings, videos, interactive modules, quizzes, and assignments. Topics include:

- ACGME program requirements

- Competencies, milestones, and EPAs

- Structure and funding of residency programs

- Billing and documentation requirements

- Recruiting and interviewing residents

- ABFM rules and requirements

- Scholarly activity for residency faculty

- Writing for academic publication

- Curriculum development

- Didactic teaching skills

- Clinical teaching skills

- Assessment and evaluation

- Feedback

- Residents in difficulty: academic and behavioral problems

Assignments require participants to gather information about their programs and to put into practice what they learn in the courses. Six of the courses contain assignments that must be reviewed and approved by the instructor, Karyn Kolman, MD. Dr Kolman is the Interim Vice Chair for Education for the University of Arizona Department of Family \& Community Medicine, and the Associate Program Director for the University of Arizona South Campus Family Medicine Residency.

To graduate from the program, participants must complete all courses and assignments and pass a final exam within a 1-year timeframe. Those who graduate receive the certificate, 30 hours of CME credit, a letter of congratulations noting the accomplishment, a letter to the graduate's program director, and a press release to distribute locally.

The Residency Faculty Fundamentals Certificate Program was developed by the STFM Graduate Medical Education (GME) Committee, STFM staff, and subject matter experts.

\section{Year 1 Results}

As of the writing of this article, 183 learners from 37 states had enrolled. While the program was designed for new residency faculty, and most self-identified as "residency faculty," learners include program directors, residents, department chairs, fellows, and medical student education directors.

Thirty-one programs have more than 1 learner enrolled.

\section{Graduate Data}

Twenty learners have completed the coursework and graduated. A list of graduates is available at http:// www.stfm.org/RFFGraduates. The average number of days between starting and completing the program was 237 ; the fastest completion was 21 days.

The average pre-test score was $55.87 \%$; the average post-test score was $96.37 \%$.

Of the 20 graduates, 9 have been faculty for less than 1 year. When asked on the program evaluation "which course did you learn the most from?," the courses selected most often (4 times each) were Curriculum Development and The Structure and Funding of Residency Programs. Comments on these courses included: "I had never really looked into how the residency program was funded. It was information that I had never thought I could obtain from my institution" and "I learned a lot about the steps to developing a solid curriculum through the modules and in practicing on the assignment."

When asked "which course did you learn the least from?," the course selected most often (4 times) was The Structure and Funding of Residency Programs. Comments included: "Not really learned the least, just learned the least I need to know to function as faculty on a day-to-day basis" and "I did learn a lot, but probably not as much new information as in the other topics because I was more familiar with this topic."

One-half the graduates indicated they were extremely satisfied with the program; $35 \%$ were satisfied, $15 \%$ were somewhat satisfied. None said they were not at all satisfied.

Eighteen of 20 graduates felt the content was at the right level for them. Two, who indicated they'd been in faculty positions for 4 to 5 years, felt it was too basic.

\section{Lessons Learned}

Over the course of the year, staff and the GME Committee gathered feedback from learners through email the graduate evaluation, a Facebook group, a gettogether at the STFM Annual Spring Conference, and during presentations at STFM and AAFP conferences.

The sheer number of participants demonstrates that there is a great need for this type of program. Graduate comments such as "I like the use of multiple instructional tools," "I liked the variety of teaching modalities used," and "I very much appreciated the varied format of information ... It kept my attention focused" confirmed that the program's combination of short interactive modules, videos, quizzes, and assignments is keeping learners engaged.

Almost unanimously, graduates have been satisfied with the course content: "I think this course gives a good foundation for the role and responsibilities of being a faculty member. It touched on all the areas of my job that I had questions and struggles with during my first year in my program. It was easy to do a module each week and feel like I accomplished learning." 
There has been mixed feedback about the assignments. Some graduates felt they were "time consuming" or "tedious" or "busy work." Many graduates and current participants have commented that assignments took much more time than they'd expected when they enrolled. Some felt like the instructions were unclear. One graduate said he/she didn't like "bugging people to help me with my assignments," although another remarked that the assignments provide an "excuse" to have conversations with "more senior people to ask questions about how things work" and helps new faculty begin "to be known in their organizations." Program directors at presentations have noted that they want their new faculty to come to them and ask questions.

Learners also asked for more information about and a direct link to the instructor.

In response, staff and the instructor clarified the instructions for the scholarly activity assignment, reduced the requirements for another assignment, increased the CME credits from 25 to 30, and created a syllabus so leaners know going in what all the assignments are and which might take longer than oth- ers. Staff also posted email links to the instructor and added a short video introduction from her.

\section{Next Steps}

Staff and the GME Committee will continue to monitor comments from learners and will make tweaks, as needed. The assignments will be discussed at the fall 2018 GME Committee meeting to determine whether any changes need to be made. A second instructor will be brought on board to help with the increasing workload. A few of the courses will be reviewed, and perhaps modified, based on the pending updates to the ACGME Program Requirements. The GME Committee is assessing the need for a Residency Faculty Intermediate Certificate Program.

A Medical School Faculty Fundamentals Certificate Program is in development, supported by the STFM Medical Student Education Committee and a variety of subject matter experts. It will launch in spring 2019.

Mary Theobald, MBA, Vice President of Communications and Programs, Society of Teachers of Family Medicine

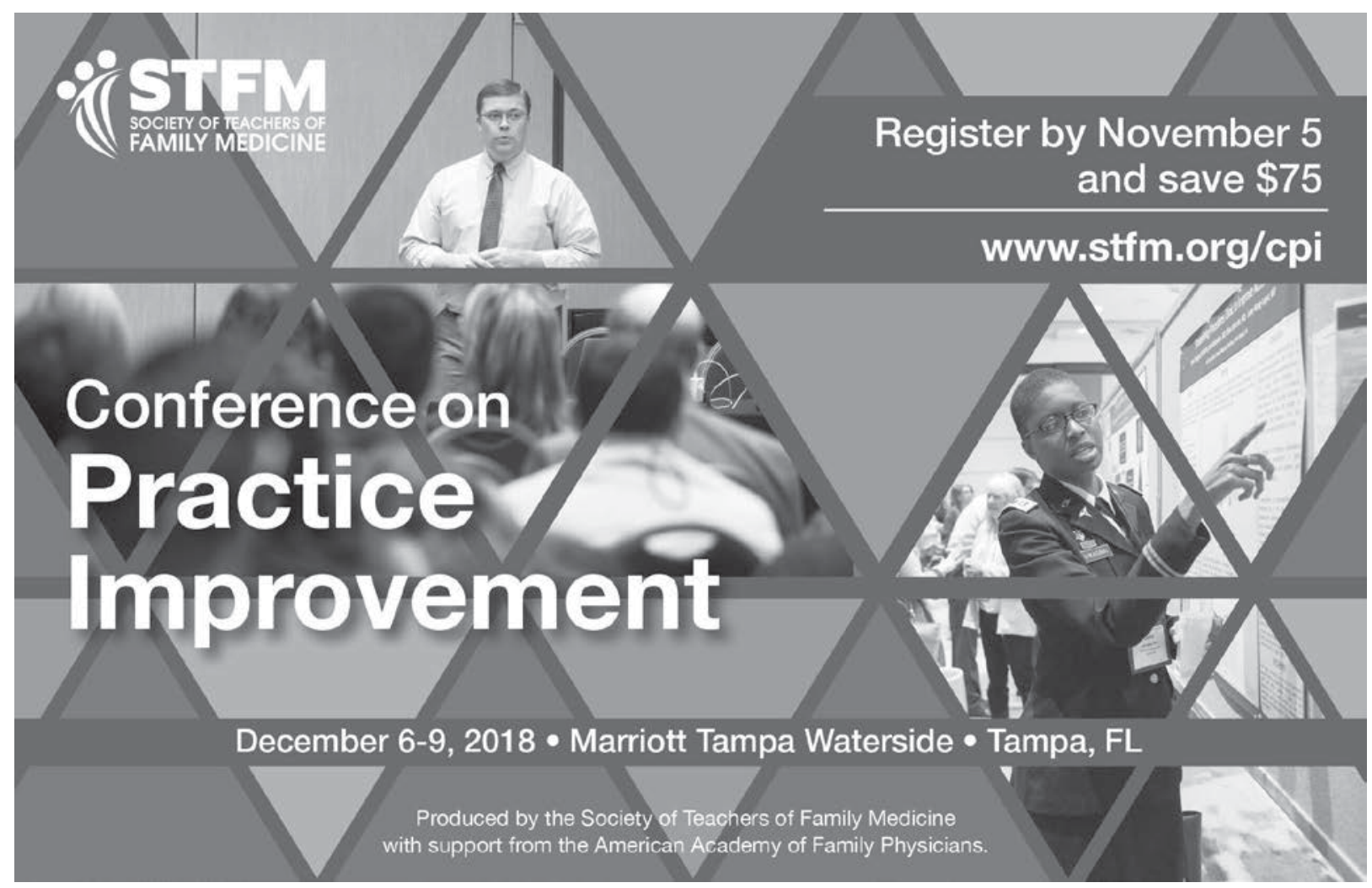

ANNALS OF FAMILY MEDICINE + WWW.ANNFAMMED.ORG + VOL. 16, NO. 5 + SEPTEMBER/OCTOBER 2018 